\title{
A study of emergency peripartum hysterectomy in a tertiary care hospital
}

\section{Jeyamani Janaki Bhaskaran, Subha Sivagami Sengodan*, Aiswarya Rangesh, Praveena Murugesan}

\begin{abstract}
Department of Obstetrics and Gynecology, Government Mohan Kumaramangalam Medical College Hospital, Salem,
\end{abstract} Tamil Nadu, India

Received: 12 March 2018

Accepted: 05 April 2018

\section{*Correspondence:}

Dr. Subha Sivagami Sengodan,

E-mail: drppsamysubha@gmail.com

Copyright: (c) the author(s), publisher and licensee Medip Academy. This is an open-access article distributed under the terms of the Creative Commons Attribution Non-Commercial License, which permits unrestricted non-commercial use, distribution, and reproduction in any medium, provided the original work is properly cited.

\section{ABSTRACT}

Background: Emergency peripartum hysterectomy is a lifesaving procedure done as a last resort to save mother's life. This study is to analyse the incidence, maternal characteristics, indications and complications following peripartum hysterectomy.

Methods: A retrospective analysis of emergency peripartum hysterectomy cases performed over a period of 3 years from January 2015 to December 2017.

Results: During the study period, 82 emergency peripartum hysterectomies were performed giving an incidence of $3.47 / 1000$ delivery. Most of the women belong to the age group of 21-30 years $(70.7 \%)$ and the women of parity two and three $(65.8 \%)$. Atonic PPH was the most common indication accounting for $59.8 \%$ of cases followed by placenta accreta (19.5\%).

Conclusions: Emergency peripartum hysterectomy remains a lifesaving procedure. Proper antenatal care, early referral, blood bank facilities and timely decision greatly influences maternal outcome.

Keywords: Atonic PPH, Obstetric hysterectomy, Placenta accreta

\section{INTRODUCTION}

Emergency peripartum hysterectomy is a very challenging obstetric procedure which is done as a last resort to save mother's life on one hand, on the other hand, the mother's reproductive capability is sacrificed. Emergency peripartum hysterectomy includes hysterectomies done during caesarean section and after vaginal delivery or any time within the puerperium. ${ }^{1}$ Incidence of emergency peripartum hysterectomy varies between 0.24-8.9 per 1000 deliveries which depends on the availability of good antenatal and obstetric care. ${ }^{2}$ Uterine atony and rupture uterus was the most common indications for emergency peripartum hysterectomy. Recent studies have indicated a change in the trend towards abnormal placentation which may be due to increasing tendency towards caesarean deliveries. Risk factors for Emergency peripartum hysterectomy includes advanced maternal age, multiparity, previous LSCS, placenta previa, operative vaginal delivery and fetalmacrosomia. ${ }^{3}$ We conducted this study to know the incidence, maternal characteristics, indications and complications of emergency peripartum hysterectomy.

\section{METHODS}

It is a retrospective analytical study conducted at Government Mohan Kumaramangalam Medical College and Hospital over a period of 3 years from January 2015December 2017. 


\section{Inclusion criteria}

- Includes all women aged 18-40 years who underwent hysterectomy after 22 weeks of gestational age and within 6 weeks of delivery

- Women who underwent hysterectomy following both caesarean section and vaginal delivery

- Includes also women aged 18-40 years who delivered outside and referred to our hospital.

\section{Exclusion criteria}

- Patient who had hysterectomy following complications of MVA like perforation of uterus, uncontrolled haemorrhage

- Hysterectomy due to associated complications like pelvic mass or any other gynaecological conditions

- Hysterectomy due to uncontrolled haemorrhage following surgical management of ectopic pregnancy.

We included all admitted women who underwent hysterectomy during caesarean section and after vaginal delivery or anytime with in the puerperium for obstetric indications like atonic PPH, placenta accreta, traumatic $\mathrm{PPH}$, rupture uterus, placenta percreta, secondary $\mathrm{PPH}$. Postoperatively patient was kept under observation in ICU until patient got stabilised and closely monitored for postoperative complications like shock, DIC, renal failure, wound infection, paralytic ileus, febrile morbidity, pneumonitis. Apart from patients who delivered in our hospital, we also included the patients who referred to our hospital after delivery. Case record and operation registers was analysed in detail about the maternal profile (age, parity etc.,), mode of delivery, indications and maternal outcome and study proceeded.

\section{RESULTS}

A total of 23,575 women delivered during our 3-year study period. Emergency peripartum hysterectomy was performed in 82 women. The incidence of emergency peripartum hysterectomy was $3.47 / 1000$ deliveries.

Table 1: Number of emergency obstetric hysterectomy.

\begin{tabular}{|c|c|c|}
\hline Year & $\begin{array}{l}\text { No. of } \\
\text { deliveries } \\
\text { per year }\end{array}$ & $\begin{array}{l}\text { No. of emergency } \\
\text { obstetric hysterectomy } \\
\text { per year }\end{array}$ \\
\hline 2015 & 6874 & 40 \\
\hline 2016 & 7686 & 27 \\
\hline 2017 & 9015 & 15 \\
\hline
\end{tabular}

$46.3 \%$ of the women were in the age group of $21-25$ years and $24.4 \%$ of the women were in the age group of 26-30 years. $17.1 \%$ if the women were in the group of 15 20years. Remaining were $>30$ years.
Table 2: Age of women.

\begin{tabular}{|ll|l|}
\hline Age (years) & No. of patients & Percentage \\
\hline $15-20$ & 14 & 17.1 \\
\hline $21-25$ & 38 & 46.3 \\
\hline $26-30$ & 20 & 24.4 \\
\hline $31-35$ & 5 & 6.1 \\
\hline $36-40$ & 5 & 6.1 \\
\hline
\end{tabular}

Majority of the women were parity two and three which contributes about $65.8 \%$. $28 \%$ of the women were primiparas and the remaining were grandmultiparas.

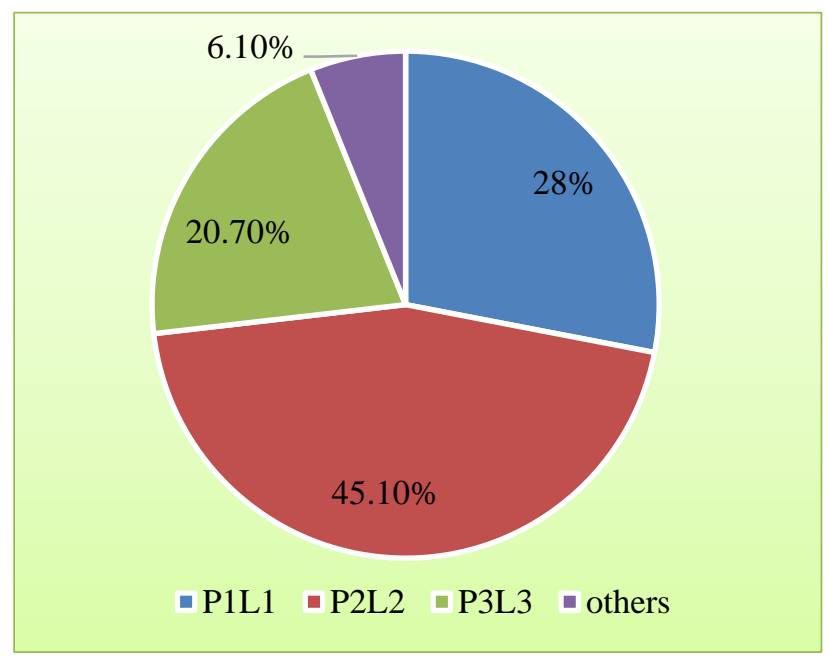

Figure 1: Parity of women.

Atonic PPH (59.8\%\%) and placenta accreta (19.5\%) were the two major indications for obstetric hysterectomy in our study. Traumatic PPH and placenta percreta contributed to $6.1 \%$ and $3.7 \%$ of the cases respectively. Other indications were rupture uterus $(9.8 \%)$ and secondary PPH (1.2\%). It was noticed that some women who underwent peripartum hysterectomy had two or more indications like placenta previa along with placenta accreta, traumatic PPH along with atonic PPH, placenta accreta was seen in a case of rupture uterus who had 2 previous LSCS.

Table 3: Indications for emergency peripartum hysterectomy.

\begin{tabular}{|lll|}
\hline Indications & No. of patients & Percentage \\
\hline Atonic PPH & 49 & 59.8 \\
\hline Placenta accreta & 16 & 19.5 \\
\hline Rupture uterus & 8 & 9.8 \\
\hline Traumatic PPH & 5 & 6.1 \\
\hline Placenta percreta & 3 & 3.7 \\
\hline Secondary PPH & 1 & 1.2 \\
\hline
\end{tabular}

Among the complications, febrile morbidity accounts for $40 \%$ of the cases, $30 \%$ of the cases which was referred from outside hospital was received in hypovolemic 
shock, $22 \%$ had paralytic ileus postoperatively. $12 \%$ of the cases developed DIC.

Table 4: Complications and postoperative morbidity.

\begin{tabular}{|l|l|}
\hline Complications & Percentage \\
\hline Febrile morbidity & 30 \\
\hline Wound infection & 5 \\
\hline Paralytic ileus & 14 \\
\hline Coagulopathy & 8 \\
\hline Bladder injury & 2 \\
\hline Shock & 22 \\
\hline Renal failure & 8 \\
\hline Pneumonitis & 4 \\
\hline
\end{tabular}

2 cases of rupture uterus were associated with bladder injury. Renal failure and pneumonitis was seen in $10 \%$ and $4 \%$ of the cases respectively.

\section{DISCUSSION}

Peripartum hysterectomy was first done after caesarean section due to atonic PPH by Porro in 1876. The incidence of obstetric hysterectomy in the present study is 3.47 per 1000 deliveries which is higher than other studies; $0.2 \%$ by sahu et al, $0.15 \%$ by Mukherjee, $0.26 \%$ by Gupta because our institution is the important referral centre for the adjoining 6 districts. ${ }^{4-6}$

Identifying risk factors and patients at high risk for emergency peripartum hysterectomy is very important in reducing maternal morbidity and mortality. Risk factors include maternal age $>35$ years, multiparity, previous caesarean delivery, repeat caesarean deliveries. ${ }^{7}$

In the present study it is more common in age group of 20-30 years which is similar to the study by Saxena et al. ${ }^{8}$ Atonic PPH was the commonest indication for emergency obstetric hysterectomy in the present study accounting for $59.8 \%$ of the cases which is similar to study by Agasthe and Marathe. ${ }^{7}$

Placenta accreta is the second most common indication in our study accounting for $19.5 \%$ of cases where as study by Nasima et al shows an incidence of $16.13 \% .^{8}$ The most common indication for emergency peripartum hysterectomy in developed countries at present is morbidly adherent placenta. Kastner et al found placenta accrete to be the most common indication for emergency peripartum hysterectomy. ${ }^{9}$

In a study by Begum the incidence of abnormal placentation was $14.28 \%$ while in our study, placenta previa and placenta accreta together accounts for $23.2 \%$. This rise in abnormal placentation is due to increasing caesarean section rate.

Another indication for obstetric hysterectomy was extension of tears and lacerations involving fornices which accounts for $6.1 \%$ of cases which is similar to study by Noor who reported $7.9 \%$ of cases. ${ }^{10}$ Postoperative pyrexia, paralytic ileus, AKI and wound infection are the common complications. Prolonged labor, intrauterine manipulation and dormant sepsis probably account for these complications. These could be prevented by early referral of these cases to wellequipped centre which can treat emergency obstetric cases promptly and efficiently

\section{CONCLUSION}

Obstetric hysterectomy is a lifesaving procedure, but decision should be prompt and treatment by experienced surgeon. Every obstetrician should be trained to perform this procedure. In spite of life saving measure, there occurs significant number of maternal deaths which can be prevented by good maternal care, active management of labor, early recognition of complications, timely referral, and easy availability of transport and blood transfusion facilities. Community education about advantages of institutional delivery or delivery by trained dais will save many such emergencies.

Funding: No funding sources

Conflict of interest: None declared

Ethical approval: The study was approved by the Institutional Ethics Committee

\section{REFERENCES}

1. Chawla J, Arora CD, Ajmani SN. Emergency Obstetric hysterectomy: a retrospective study from a teaching hospital in North India over eight years. Oman Med J.2015;30(3):181-6.

2. Lovina SM, Machado. Emergency peripartum hysterectomy: incidence, indications, risk factors and outcome. North Am J Med Sci. 2011;3(8):358-61.

3. Carvalho FJ, Cubal A, Torres S, Costa F, Carmo OD. Emergency peripartum hysterectomy: A 10-year review. ISRN Emerg Med. 2012;2012.

4. Sahu L, Chakravertty B, Panda S. Hysterectomy for obstetric emergencies. J Obstet Gynecol India 2004;54:34-6.

5. Mukherjee P, Mukherjee G, Das C. Obstetric hysterectomy: a review of 107 cases. J Obstet Gynecol India. 2002;52:34-6.

6. Gupta S, Dave A, Bandi G. Obstetric hysterectomy in modern day obstetrics: a review of 175 cases over a period of 11 years. J Obstet Gynecol India 2001;51:91-3.

7. Whiteman MK, Kuklina E, Hillis SD, Jamieson DJ, Meikle SF, Posner SF, et al. Incidence and determinants of peripartum hysterectomy. Obstet Gynecol.2006;108(6):1486-92.

8. Saxena SV, Bagga R, Jain V, Gopalan S. Emergency peripartum hysterectomy. Int J Gynaecol Obstet. 2004;85:172-3. 
9. Agashe AP, Marathe SS. Obstetric hysterectomy (a review of 50 cases from January 1987 to August 1990). J Obstet Gynecol India. 1991;45:490:3.

10. Siddiq N, Ghazi A, Jabbar S, Ali T. Emergency obstetrical hysterectomy a lifesaving procedure in obstetrics. Pak J Surg. 2007;23(3):217-9.
Cite this article as: Bhaskaran JJ, Sengodan SS,

Rangesh A, Murugesan P. A study of emergency peripartum hysterectomy in a tertiary care hospital. Int J Reprod Contracept Obstet Gynecol 2018;7:1934-7. 